\title{
Synthesis and characterization of a novel bisphthalonitrile containing benzoxazine
}

\author{
G. P. Cao, W. J. Chen, J. J. Wei, W. T. Li, X. B. Liu* \\ Institute of Microelectronic \& Solid State Electronic, State Key Laboratory of Electronic Thin Films \& Integrated \\ Devices, University of Electronic Science and Technology of China, Chengdu 610054, China
}

Received 4 April 2007; accepted in revised form 3 July 2007

\begin{abstract}
The novel bisphthalonitrile containing benzoxazine (BPNBZ) has been synthesized using bisphenol-A, 4-aminophenoxylphthalonitrile and paraformaldehyde. The structure of the monomer was supported by FTIR spectroscopy, ${ }^{1} \mathrm{H}-\mathrm{NMR}$, and ${ }^{13} \mathrm{C}$-NMR spectra, which have exhibited that the reactive benzoxazine ring and cyano groups exist in molecular structure of BPNBZ. The cure reaction of BPNBZ was monitored by the disappearance of the nitrile peak and the tri-substituted benzene ring that is attached with oxazine ring peak at $2231,951 \mathrm{~cm}^{-1}$. The thermal polymerization of the BPNBZ was studied by differential scanning calorimetry (DSC) and dynamic rheometer. It was shown that the bisphthalonitrile containing benzoxazine had completely cured with two-stage polymerization mechanisms according to oxazine ring-opening and phthalonitrile ring-forming. The thermal decomposition behaviors of the polymer were examined by thermogravimetry analysis (TGA) in nitrogen and in air. The materials achieve char yields above $73 \%$ under nitrogen at $800^{\circ} \mathrm{C}$ and above $78 \%$ under air at $600^{\circ} \mathrm{C}$, which exhibited the cured resin has good thermal stability and thermo-oxidative stability.
\end{abstract}

Keywords: thermosetting resins, thermal properties, thermal polymerization, bisphthalonitrile containing benzoxazine

\section{Introduction}

The aerospace industry and space programs have created new demands for even higher temperature polymers. There has been increasing interest in phthalonitrile polymers [1-7], owing to their excellent thermal and thermo-oxidative stability, high char yield, good chemical inertness, abrasion resistance, and flame resistance. But, there are several challenges to overcome with regard the processing of these materials with higher melting temperature and high processing temperature.

In recent years, the development of the benzoxazine-based family of phenolic resins has attracted significant attention. The attractive characteristics of benzoxazine polymers include low melt viscosity, no release of volatiles during cure and no need for harsh catalysts, high thermal stability, good mechanical properties, excellent electrical properties and molecular design flexibility [14-16]. So in order to achieve low melt temperature of phthalonitrile, the presence of aromatic oxazine in the phthalonitrile molecular structure is necessary [11]. In this paper, we report on the synthesis of a bisphthalonitrile monomer containing benzoxazine and the properties of its polymer. Thermal polymerization of this monomer is relatively easy, because of the active benzoxazine ring in the backbone [8-11]. The focus of this research develops a novel bisphthalonitrile containing benzoxazine which expected that this bisphthalonitrile will contribute to the cross-link network formation by its own ring-forming polymerization. 


\section{Experimental}

\subsection{Materials}

All chemicals were used as received. Paraformaldehyde (CP), toluene $(99.5 \%)$, N-N-dimethylformamide (DMF, 99.5\%), potassium carbonate (99\%), and 1,4-dioxane (99\%) were obtained from Tianjin BODI Chemicals. 4-nitrophthalonitrile (99\%) was obtained from Alpha Chemical (Dezhou) Co. Ltd. 4-Aminophenol (CP) was obtained form Sinopharm Chemical Reagent Co., Ltd. BisphenolA was obtained form Tianjin Guangfu Fine Chemical Research Institute. All solvents used were certified A.C.S grade and used as received.

\subsection{Synthesis}

\subsubsection{Synthesis of \\ 4-aminophenoxylphthalonitrile}

To a $250 \mathrm{ml}$ three neck round-bottom flask equipped with a mechanical stirrer, refluxing condenser, and 4-nitrophthlonitrile (34.6 g, $0.2 \mathrm{~mol}$ ), 4-Aminophenol (21.8 g, $0.2 \mathrm{~mol})$, potassium carbonate $(30 \mathrm{~g}$,), and DMF $(120 \mathrm{ml})$ were added. The reaction mixture refluxed at $85^{\circ} \mathrm{C}$ for $6 \mathrm{~h}$. After $6 \mathrm{~h}$, the mixture was precipitated into dilute $\mathrm{NaOH}$ ( $1 \mathrm{~mol} / \mathrm{l})$ using an additional funnel with slow addition rate. The brown precipitate was filtered and dried in vacuum oven at $70^{\circ} \mathrm{C}$ shown in Figure 1. Melting point $\left(T_{m}\right): 134^{\circ} \mathrm{C}$; typical IR data: $3457 \mathrm{~cm}^{-1}\left(-\mathrm{NH}_{2}\right), 2231 \mathrm{~cm}^{-1}(-\mathrm{CN}), 1247 \mathrm{~cm}^{-1}$ (stretch, C-O-C), $1493 \mathrm{~cm}^{-1}$ (1, 2 and 4 substitution of benzene ring), $830 \mathrm{~cm}^{-1}$ (1, 4 substitution of benzene ring).

\subsubsection{Synthesis of the novel bisphthalonitrile containing benzoxazine (BPNBZ)}

To a $250 \mathrm{ml}$ three neck round-bottom flask equipped with a mechanical stirrer, refluxing condenser, the 4-aminophenoxylphthalonitrile $(23.4 \mathrm{~g}$, $0.1 \mathrm{~mol})$, bisphenol-A $(11.4 \mathrm{~g}, 0.05 \mathrm{~mol})$, and Paraformaldehyde $(6 \mathrm{~g}, 0.2 \mathrm{~mol})$ were dissolved in $40 \mathrm{ml}$ of 1,4-dioxane and $20 \mathrm{ml}$ of toluene and the reaction mixture refluxed at $110^{\circ} \mathrm{C}$ for $5 \mathrm{~h}$. Then, the solvent was evaporated using a vacuum pump, and the crude product was obtained. Then, the crude product was dissolved in DMF and precipitated into the dilute $\mathrm{NaOH}(1 \mathrm{~mol} / \mathrm{l})$. The brown precipitate was filtered through a glass filter under vacuum and dried in vacuum oven at $70^{\circ} \mathrm{C}$, and the purified bisphthalonitrile containing benzoxazine (BPNBZ) was obtained, shown in Figure 1 [11]. The typical IR characteristics data: $2231 \mathrm{~cm}^{-1}$ $(-\mathrm{CN}), 1503,951 \mathrm{~cm}^{-1}$ [12, 13] (tri-substituted benzene ring that is attached with oxazine ring), 1247, $1032 \mathrm{~cm}^{-1}$ (stretch, C-O-C) [12, 13], 1086, $830 \mathrm{~cm}^{-1}$ (stretch C-N-C) [12], $1420 \mathrm{~cm}^{-1}\left(\mathrm{CH}_{2}\right.$ antisymmetric stretch); ${ }^{1} \mathrm{H}-\mathrm{NMR}\left(400 \mathrm{MHz}, \mathrm{CDCl}_{3}\right)$ $\delta$ (ppm): 1.621-1.627 $\left(\mathrm{CH}_{3}\right), 4.615-4.629\left(\mathrm{CH}_{2}\right)$; $5.350\left(\mathrm{~N}-\mathrm{CH}_{2}-\mathrm{O}\right), 6.740-6.745(\mathrm{~N}-\mathrm{Ar}-\mathrm{H}), 6.762-$ 6.907 (ortho to $\mathrm{N}-\mathrm{Ar}-$ ). ${ }^{13} \mathrm{C}-\mathrm{NMR}(400 \mathrm{MHz}$,

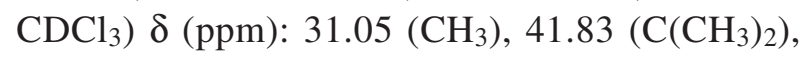
$51.03\left(\mathrm{Ar}-\mathrm{CH}_{2}-\mathrm{N}\right), 79.10\left(\mathrm{~N}-\mathrm{CH}_{2}-\mathrm{O}\right), 115.46$ $(\mathrm{Ar}-\mathrm{C} \equiv \mathrm{N}), 121.01\left(\mathrm{C}-\mathrm{CH}_{2}-\mathrm{N}\right), 143.44\left(\mathrm{C}_{11}\right)$, $146.94\left(\mathrm{C}_{8}\right), 162.35\left(\mathrm{C}_{7}\right)$.

\subsubsection{Thermal polymerization of the monomer}

The BPNBZ monomer could be polymerized by heating. The conditions of the BPNBZ polymeriza-

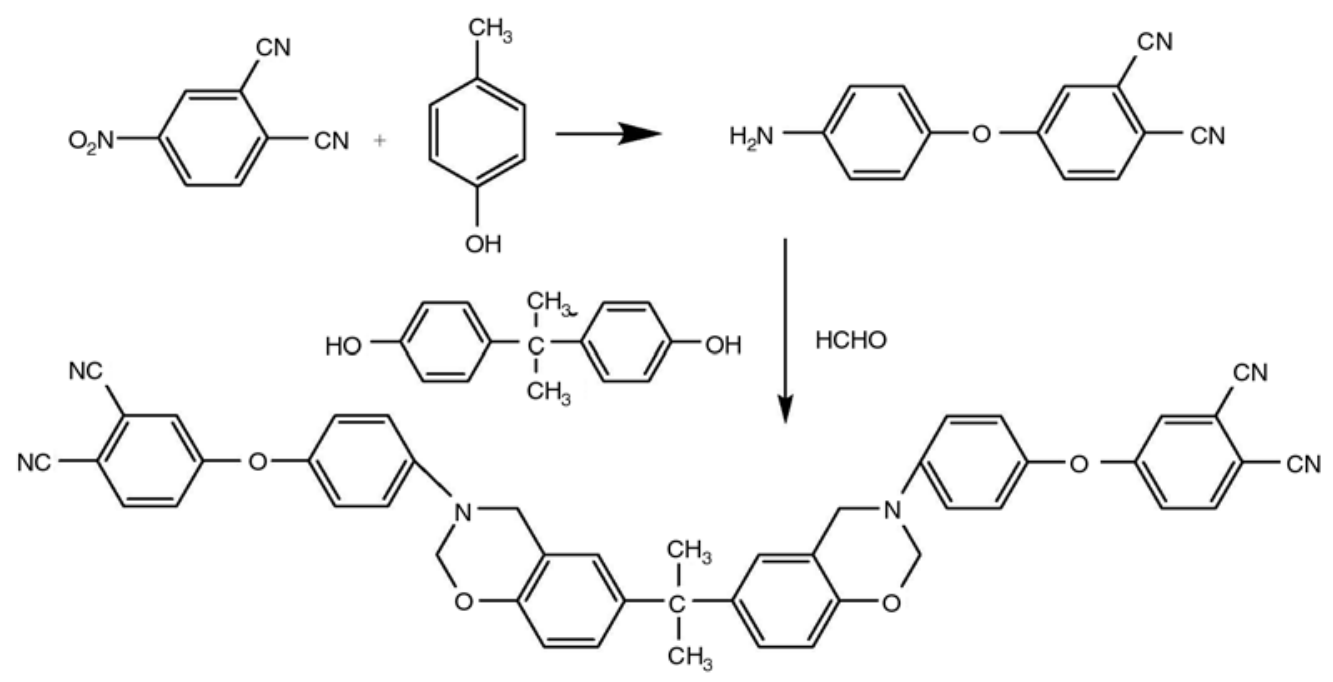

Figure 1. The synthesis of the bisphthalonitrile containing benzoxazine 
Table 1. The cured schedule of the prepolymer and polymer

\begin{tabular}{|c|c|}
\hline Sample & Time and temperature \\
\hline b & $160^{\circ} \mathrm{C}-12 \mathrm{~h}$ \\
\hline c & $160^{\circ} \mathrm{C}-12 \mathrm{~h} 180^{\circ} \mathrm{C}-12 \mathrm{~h}$ \\
\hline d & $160^{\circ} \mathrm{C}-12 \mathrm{~h} 180^{\circ} \mathrm{C}-12 \mathrm{~h} 200^{\circ} \mathrm{C}-8 \mathrm{~h}$ \\
\hline e & $160^{\circ} \mathrm{C}-12 \mathrm{~h} 180^{\circ} \mathrm{C}-12 \mathrm{~h} 200^{\circ} \mathrm{C}-8 \mathrm{~h} 220^{\circ} \mathrm{C}-6 \mathrm{~h}$ \\
\hline f & $160^{\circ} \mathrm{C}-12 \mathrm{~h} 180^{\circ} \mathrm{C}-12 \mathrm{~h} 200^{\circ} \mathrm{C}-8 \mathrm{~h} 220^{\circ} \mathrm{C}-6 \mathrm{~h} 250^{\circ} \mathrm{C}-6 \mathrm{~h}$ \\
\hline
\end{tabular}

tion were listed in Table 1 . The cured samples were heated at $160^{\circ} \mathrm{C}$ for $12 \mathrm{~h}, 180^{\circ} \mathrm{C}$ for $12 \mathrm{~h}, 200^{\circ} \mathrm{C}$ for $8 \mathrm{~h}, 220^{\circ} \mathrm{C}$ for $6 \mathrm{~h}$ and $250^{\circ} \mathrm{C}$ for $6 \mathrm{~h}$ consecutively. A hard shiny blue-black solid was obtained.

\subsubsection{Characterizations}

The structure of monomer and resins were characterized in $\mathrm{KBr}$ pellets at Shimadzu FTIR8400S. The resins with different cured extent were prepared in DSC by heating from 50 to 180 (b), 200 (c), 220 (d), 250 (e) and $275^{\circ} \mathrm{C}$ (f) at a heating rate $10^{\circ} \mathrm{C} / \mathrm{min}$ respectively.

${ }^{1} \mathrm{H}-\mathrm{NMR}$ and ${ }^{13} \mathrm{C}-\mathrm{NMR}$ spectra were obtained using a Bruker AV400 nuclear magnetic resonance spectrometer (NMR) at a proton frequency of $400 \mathrm{MHz}$ and the corresponding carbon frequency. The solvent is $\mathrm{CDCl}_{3}$.

The thermal behaviors of monomer and resins were investigated by the differential scanning calorimetry (DSC) and thermogravimetry analysis (TGA). The differential scanning calorimetry (DSC) was performed on TA Instruments Modulated DSCQ100 with a heating rate of $10^{\circ} \mathrm{C} / \mathrm{min}$ and a nitrogen flow rate of $50 \mathrm{ml} / \mathrm{min}$. All samples were crimped in hermetic aluminum pans with lids. The thermogravimetry analysis (TGA) was performed on the TA instruments Q50 thermogravimetric analyzer with a heating rate of $20^{\circ} \mathrm{C} / \mathrm{min}$ and a nitrogen flow rate of $50 \mathrm{ml} / \mathrm{min}$ or an air flow rate of $50 \mathrm{ml} / \mathrm{min}$.

The dynamic rheological measurements were carried out using TA Instruments AR-G2 Oscillatory Rheometer with a heating rate of $10^{\circ} \mathrm{C} / \mathrm{min}$ and the frequency of $10 \mathrm{~Hz}$ under air atmosphere.

\section{Results and discussion}

\subsection{Characterization of structure of BPNBZ and resin}

The structure of BPNBZ as shown in Figure 1 was verified by ${ }^{1} \mathrm{H}-\mathrm{NMR}$ and ${ }^{13} \mathrm{C}-\mathrm{NMR}$ spectroscopy and the corresponding spectrum was shown in Figure 2 and 3. In ${ }^{1} \mathrm{H}-\mathrm{NMR}$, resonances appearing at 4.63 and $5.35 \mathrm{ppm}$ are assigned to the methylene protons in the oxazine ring of BPNBZ [13]. The prominent resonance at 1.621 and $1.627 \mathrm{ppm}$ in the aromatic frequency corresponds to methyl of the monomer. Furthermore, the structure of the monomer is confirmed by using ${ }^{13} \mathrm{C}-\mathrm{NMR}$ and the corresponding chemical shifts are shown in Figure 3 , according to chemical shift values, the peak at $79.5 \mathrm{ppm}$ indicates the characteristic resonance of $-\mathrm{CH}_{2}-$ in oxazine ring, and the peak at $115 \mathrm{ppm}$ is the characteristic resonance of $-\mathrm{CN}$. Along with the excellent agreement between the calculated and observed data of the elemental analysis for the purified sample, it shows that the targeted compounds were obtained in high purity [13].

The FTIR spectrum of BENBZ is shown in Figure $4 \mathrm{a}$. The appearance of $-\mathrm{CN}$ at $2231 \mathrm{~cm}^{-1}$ and tri-substituted benzene ring that is attached with oxazine ring at 1503 , and $951 \mathrm{~cm}^{-1}$ can be observed. The band at $1247 \mathrm{~cm}^{-1}$ is assigned to the $\mathrm{C}-\mathrm{O}-\mathrm{C}$ antisymmertic, while the band at $1032 \mathrm{~cm}^{-1}$ is assigned to the $\mathrm{C}-\mathrm{O}-\mathrm{C}$ symmetric stretch $[12,13]$. The antisymmertic and symmetric stretch of the C-N-C is observed at 1086, $830 \mathrm{~cm}^{-1}$. These results show a novel bisphthalonitrile containing benzoxazine could be synthesized by this technique.

The FTIR spectra of resins are shown in Figure 4. The peaks at 951, 1503, 2231, 1360, 1521, 1640 and $3280 \mathrm{~cm}^{-1}$ show changes in intensity as a function of cure temperature. To observe the thermal polymerization and curing reaction mechanisms of BPNBZ, we use the non-isothermal polymerization techniques by DSC instrument scanning to schedule program, so as to explain the way of thermal polymerization and the structures of crosskicked networks. From these results, the changes of all characteristic peaks are no apparent when scanning from 50 to $180^{\circ} \mathrm{C}$ using non-isothermal polymerization reactions by DSC instrument (Figure 4b), the intensity of the peak at 951 and $1503 \mathrm{~cm}^{-1}$ decreased faintly after scanning to $200^{\circ} \mathrm{C}$ shown in Figure $4 \mathrm{c}$. At the same time, the peak attributed phenolic hydroxyl group at $3300-3400 \mathrm{~cm}^{-1}$ was enhanced, suggesting the polymerization reaction of oxazine ring-opening appears (Figure 4d). After scanning to $250^{\circ} \mathrm{C}$, the band of tri-substituted benzene ring that is attached with oxazine ring disap- 


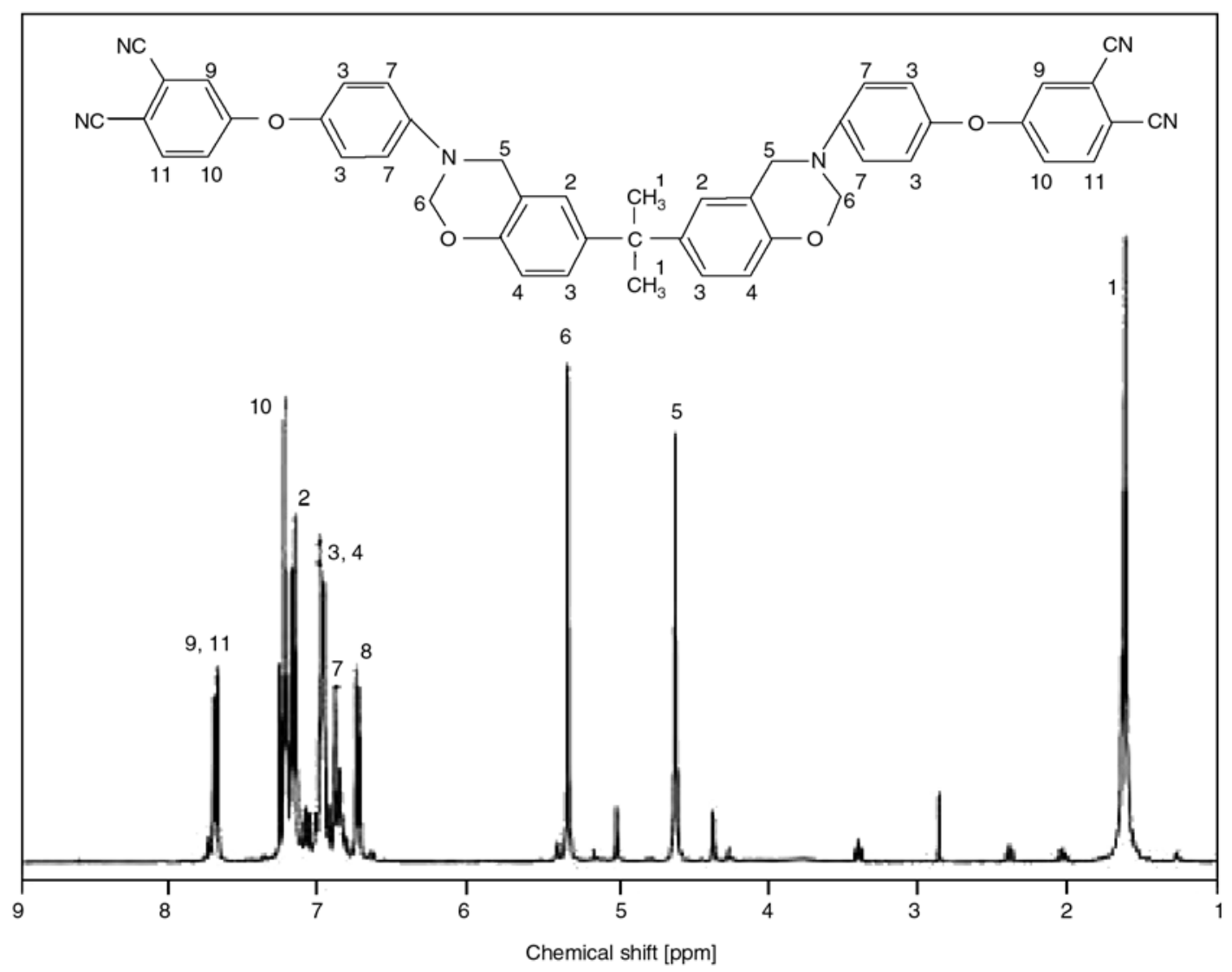

Figure 2. ${ }^{1} \mathrm{H}-\mathrm{NMR}$ spectrum of $\mathrm{BPNBZ}$ in $\mathrm{CDCl}_{3}$

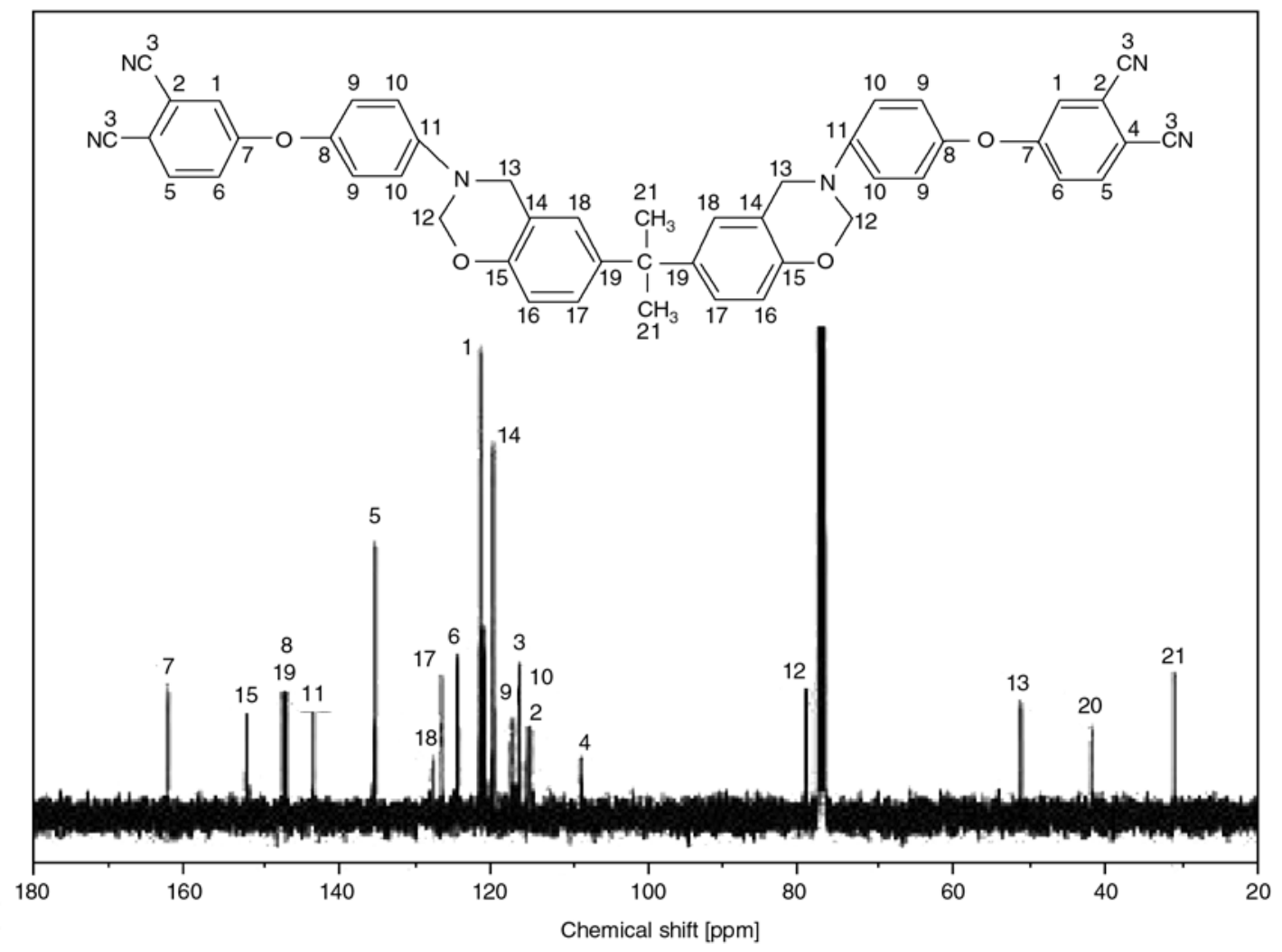

Figure 3. ${ }^{13} \mathrm{C}-\mathrm{NMR}$ spectrum of $\mathrm{BPNBZ}$ in $\mathrm{CDCl}_{3}$ 


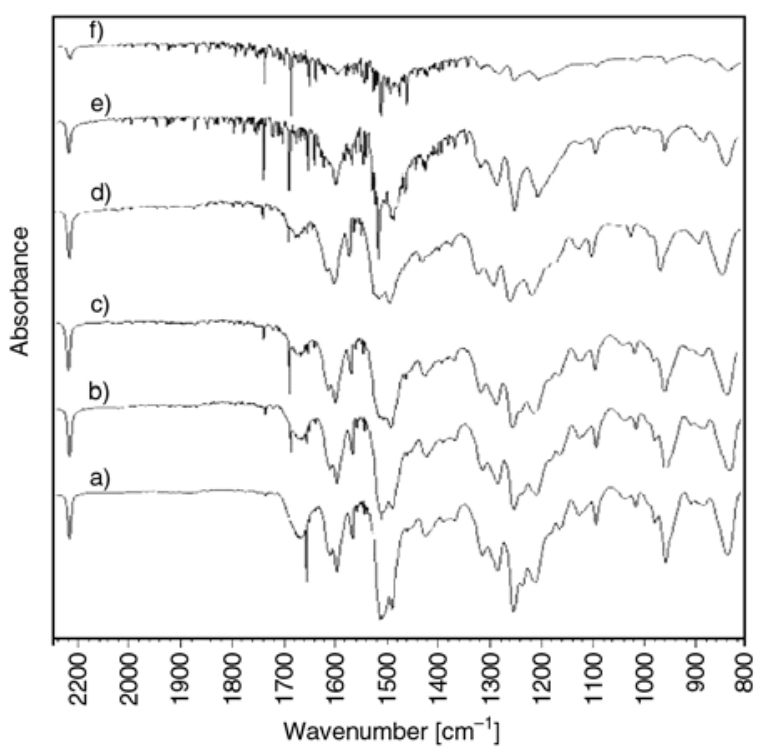

Figure 4. FTIR spectra of the monomer (a), partially cured resin (b), (c), (d), (e) and (f)

pears at $1503 \mathrm{~cm}^{-1}$ and the prominent band of tetrasubstituted appears at $1500 \mathrm{~cm}^{-1}$, suggesting benzoxazine polymerization via ring-opening is complete. According to the decrease of intensity of the peak at $2231 \mathrm{~cm}^{-1}$ and the appearance of new peaks at 1521, $13601637(-\mathrm{C}=\mathrm{N}-)$ and $3275 \mathrm{~cm}^{-1}$ $(\mathrm{N}-\mathrm{H})$, which are contributed to the characteristic absorptions of triazinne and phthalocyaine, suggest the polymerization reaction of $-\mathrm{CN}$ groups has happened, as shown in Figure 4e. The Figure 5 indicates the typical FTIR spectra of the ring-forming proceedings of $-\mathrm{CN}$ groups, the reactions are enhanced with the elevating of temperature. After scanning to $275^{\circ} \mathrm{C}$, the peak of $-\mathrm{CN}$ at $2231 \mathrm{~cm}^{-1}$ decreases clearly, shown in Figure 4f. These spectral observations suggest that multiple reaction

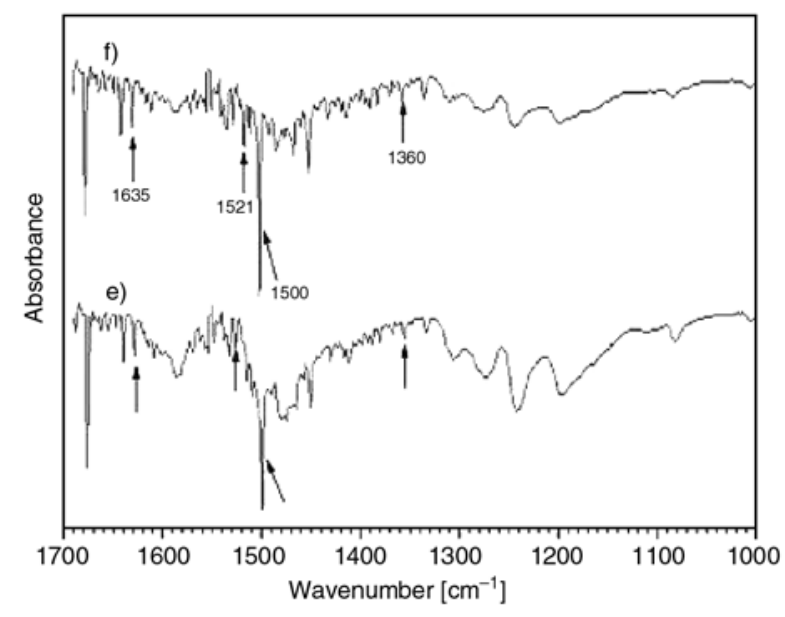

Figure 5. FTIR spectra of the pre-cured resins mechanisms may be operational in the cure reactions of bisphthalonitrile containing benzoxazine.

\subsection{DSC and TGA analysis}

The thermal polymerization reactions of the monomer were studied by DSC as shown in Figure 6a. The DSC trace has two well resolved polymerization peaks. The first polymerization peak at the temperature range from 170 to $265^{\circ} \mathrm{C}$ is mainly attributed to the oxazine ring-opening polymerization, and the second peak at the temperature range from 265 to $300^{\circ} \mathrm{C}$ owes to the bisphthalonitrile ring-forming polymerization. This result was supported by the FTIR spectra results. From Figure 6, the cured extent of resin increased as a function of cure temperature and time, the peaks decreased with the increase of time and temperature. The resins with different cured extent are shown in Table 1, we found that the first peak had eliminated after curing at $200^{\circ} \mathrm{C}$ for $8 \mathrm{~h}$ (Figure $6 \mathrm{~d}$ ), and from Figure $6 \mathrm{e}$ and $\mathrm{f}$, the second peak had eliminated basically after curing at $220^{\circ} \mathrm{C}$ for $6 \mathrm{~h}$ and $250^{\circ} \mathrm{C}$ for $5 \mathrm{~h}$. There is a peak at the temperature range from 325 to $360^{\circ} \mathrm{C}$, the temperature $325^{\circ} \mathrm{C}$ is postcure temperature and the $360^{\circ} \mathrm{C}$ is the initial decomposition temperature, which can be support by the TGA results. As these results, it means that the bisphthalonitrile containing benzoxazine had completely cured with two-stage polymerization mechanisms according to oxazine ring-opening and phthalonitrile ring-forming.

The TGA curves of the polymers as shown in Figure 7. The initial decomposition temperatures $\left(T_{i d}\right)$ of the polymer under nitrogen and air are about

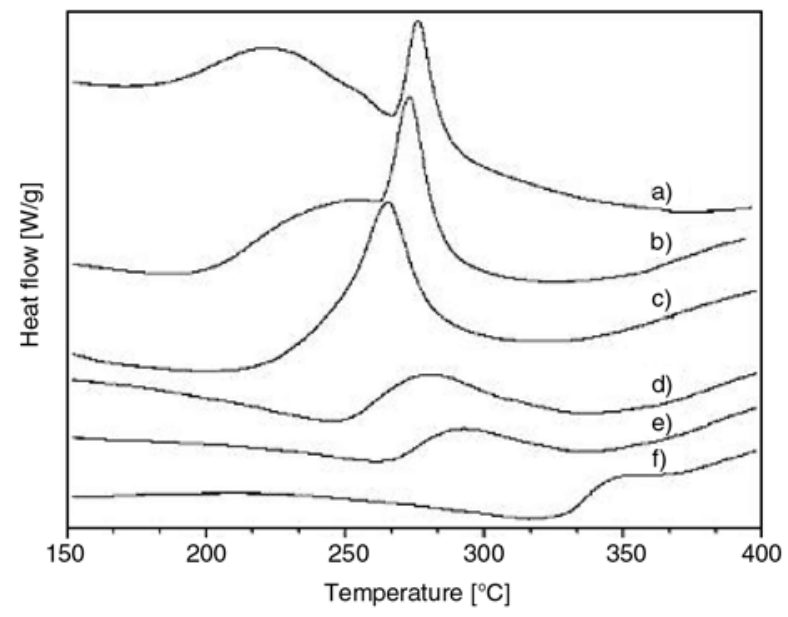

Figure 6. The DSC curves of the monomer (a) and the pre-cured resin (b), (c), (d), (e) and (f) 


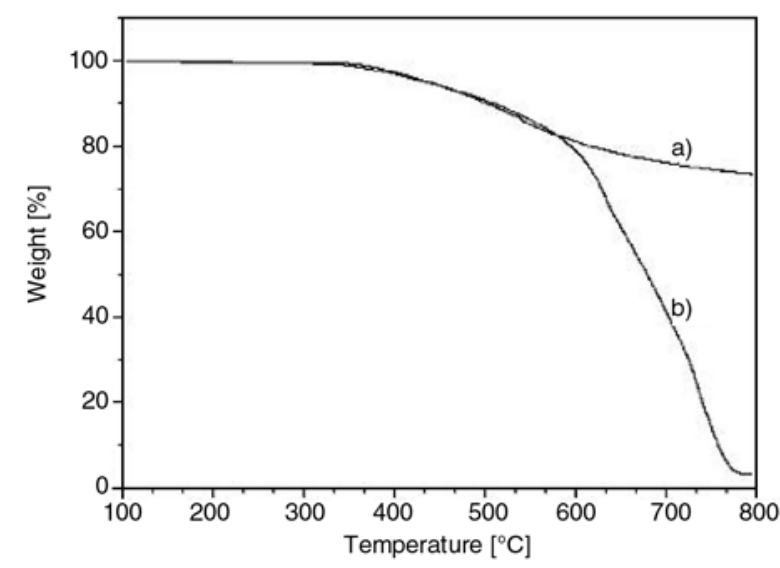

Figure 7. The TGA curves of the polymer a) in $\mathrm{N}_{2}, \mathrm{~b}$ ) in air

343.38 and $354.06^{\circ} \mathrm{C}$, respectively. The temperatures at weight loss 5 and $10 \%$ in nitrogen atmosphere are 437.50 and $504.59^{\circ} \mathrm{C}$ and in air atmosphere are 434.63 and $504.29^{\circ} \mathrm{C}$, respectively. The char yield at $800^{\circ} \mathrm{C}$ under nitrogen is $73.65 \%$ and at $600^{\circ} \mathrm{C}$ under air is $78.66 \%$. In Table 2, the thermal properties of BPNBZ are summarized and compared to other phthalonitrile. The thermal properties of BPNBZ under nitrogen are as well as or decrease slightly than the other two monomers, but there is a significant improvement of the BPNBZ thermal properties under air than the other two. Therefore, the BPNBZ can be used for making heat-resistance high performance composites.

\subsection{The rheological behavior}

Figure 8 is relationship between rheological behaviors and temperature under curing process of bisphthalonitrile containing benzoxazine. Two transitions of $G^{\prime}$ appear from 200 to $300^{\circ} \mathrm{C}$ and two cross

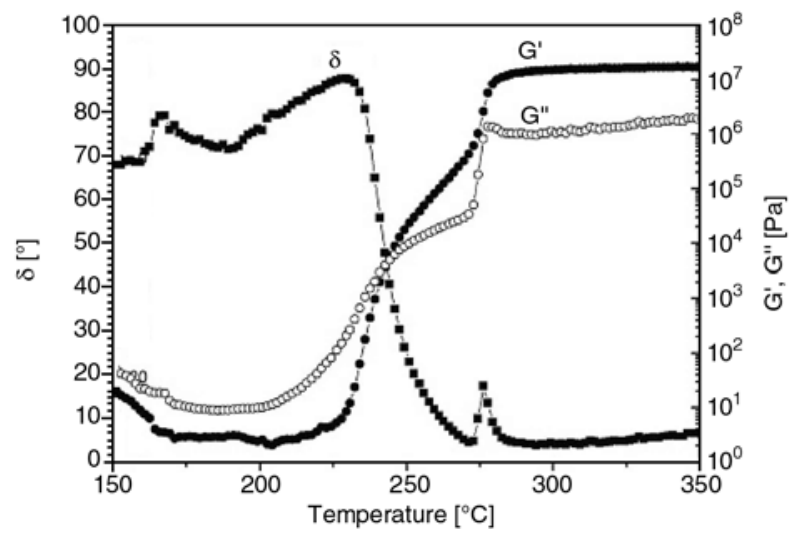

Figure 8. The rheological behaviors of the BPNBZ under non-isothermal curing

points of $G$ ' and $G$ " were observed at 242.7 and $276.1^{\circ} \mathrm{C}$, respectively. The $G$ " has two apparent peaks. The first peak ranges from 200.9 to $242.7^{\circ} \mathrm{C}$, and the second peak ranges from 242.7 to $276.1^{\circ} \mathrm{C}$. The Delta curve appears two sharp peaks; the temperature of peak top is 230.7 and $276.1^{\circ} \mathrm{C}$ respectively. As these results, the former suggests primary polymerization of oxazine ring-opening, and the later suggests the bisphthalonitrile polymerizations of nitrile groups. So, it means that the bisphthalonitrile containing benzoxazine had completely cured with two-stage polymerization mechanisms which are consistent with the DSC results.

\section{Conclusions}

The novel bisphthalonitrile containing benzoxazine (BPNBZ) has been synthesized using bisphenol-A, 4-aminophenoxylphthalonitrile and paraformaldehyde. The structure of the monomer was supported by FTIR spectroscopy, ${ }^{1} \mathrm{H}-\mathrm{NMR}$, and ${ }^{13} \mathrm{C}$-NMR

Table 2. summary of TGA results

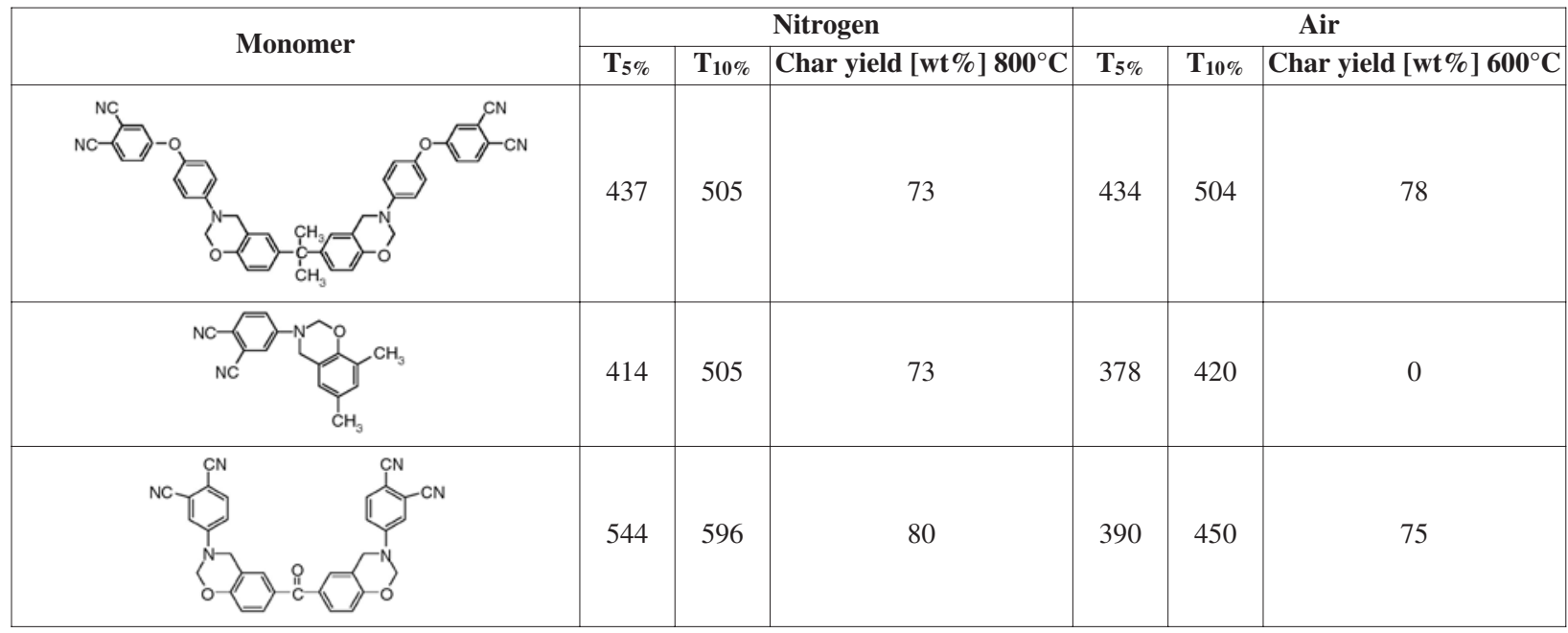


spectra, which have exhibited that the reactive benzoxazine ring and cyano groups exist in molecular structure of BPNBZ. The cure reaction mechanism of BPNBZ was monitored by the disappearance of the nitrile peak and the tri-substituted benzene ring that is attached with oxazine ring peak at 2231, $951 \mathrm{~cm}^{-1}$. The bisphthalonitrile containing benzoxazine polymer possesses excellent thermal stability, thermal-oxidation stability and high char yield in nitrogen and air. The materials char yields achieved $73 \%$ at $800^{\circ} \mathrm{C}$ under nitrogen and $78 \%$ at $600^{\circ} \mathrm{C}$ under air. The temperatures at weight loss $5 \%$ and $10 \%$ under air are 434.63 and $509.29^{\circ} \mathrm{C}$, respectively. According to the observations of thermal polymerization by DSC and dynamical rheology, the curing process of bisphthalonitrile containing benzoxazine has two stages polymerization mechanisms according to oxazine ring-opening and phthalonitrile ring-forming. The cured extent is a function of temperature and time. It can be used as a matrix of advanced composites.

\section{Acknowledgements}

This project was sponsored by 'Excellent Talents Program' of University of Electronic Science and Technology of China.

\section{References}

[1] Keller T. M., Dominguez D. D.: High temperature resorcinol-based phthalonitrile polymer. Polymer, 46, 4614-4618 (2005).

[2] Warzel M. L., Keller T. M.: Tensile and fracture properties of a phthalonitrile polymer. Polymer, 34, 663666 (1993).

[3] Dominguez D. D., Jones H. N., Keller T. M.: The effect of curing additive on the mechanical properties of phthalonitrile-carbon fiber composites. Polymer Composites, 25, 554-561 (2004).

[4] Sastri S. B., Armistead J. P., Keller T. M.: Phthalonitrile-carbon fiber composites. Polymer Composites, 17, 816-822 (1996).
[5] Zhang J., Liu X., Wen H., Xie M., Cai X.: Investigation of the properties of phthalocyanine resin containing bismaleimide groups. Polymer International, 42, 363-366 (1997).

[6] Dominguez D. D., Keller T. M.: Properties of phthalonitrile monomer blends and thermosetting phthalonitrile copolymers. Polymer, 48, 91-97 (2007).

[7] Laskoski M., Dominguez D. D., Keller T. M.: Synthesis and properties of a bisphenol A based phthalonitrile resin. Journal of Polymer Science Part A: Polymer Chemistry, 43, 4136-4143 (2005).

[8] Kim H. J., Brunoyska Z. B., Ishida H.: Molecular characterization of the polymerization of acetylenefunctional benzoxazine resins. Polymer, 40, 18151822 (1999).

[9] Rimdusit S., Ishida H.: Development of new class of electronic packaging materials based on ternary systems of benzoxazine, epoxy, and phenolic resins. Polymer, 41, 7941-1949 (2000).

[10] Takeichi T., Guo Y., Agag T.: Synthesis and characterization of poly (urethane-benzoxazine) films as novel type of polyurethane/phenolic resin composites. Journal of Polymer Science Part A: Polymer Chemistry, 38, 4165-4176 (2000).

[11] Brunovska Z., Lyon R., Ishida H., Riga A., Collins R.: Thermal properities of phthalonitrile functional polybenzoxazines. Thermochimica Acta, 357-358, 195 203 (2000).

[12] Dunkers J., Ishida H.: Vibrational assignments of 3alkyl-2, 4-dihydro-1, 3-benzoxazines. Spectrochimia Acta, Part A: Molecular Spectroscopy, 51, 1061-1074 (1995).

[13] Ishida H., Ohba S.: Synthesis and characterization of maleimide and norbornene functionalized benzoxazines. Polymer, 46, 5588-5595 (2005).

[14] Salamone J. C.: Polymeric materials encyclopedia. New York, CRC Press (1996).

[15] Ishida H. J., Allen D. J.: Physical and mechanical characterization of near-zero shrinkage polybenzoxazine. Polymer Science, Part B: Polymer Physics, 34, 1019-1030 (1996).

[16] Ishida H., Low H. Y.: A study on the volumetric expansion of benzoxazine-based phenolic resin. Macromolecules, 30, 1099-1106 (1997). 